\title{
TEKNIK PENGAMBILAN, IDENTIFIKASI, DAN PENGHITUNGAN KELIMPAHAN PLANKTON DI PERAIRAN TELUK JAKARTA
}

\author{
Enda Suhenda \\ Teknisi Litkayasa pada Balai Riset Perikanan Laut, Muara Baru-Jakarta \\ Teregristasi I tanggal: 23 Juli 2008; Diterima setelah perbaikan tanggal: 6 Agustus 2008; \\ Disetujui terbit tanggal: 15 Agustus 2008
}

\section{PENDAHULUAN}

Plankton adalah biota yang pada umumnya berukuran sangat kecil sehingga tidak dapat dilihat dengan mata biasa, hidup menghanyut dan terbawa gerakkan air ke mana saja. Namun hewan ini dapat bergerak sendiri. Plankton dibagi menjadi 2, yaitu plankton tumbuh-tumbuhan (fitoplankton) dan plankton hewan (zooplankton). Di antara zooplankton ada larva dari berbagai jenis biota laut. Untuk melihat atau mengamati berbagai jenis plankton dapat mempergunakan alat mikroskop.

Plankton dapat dimanfaatkan sebagai makanan alami yang dapat dikonsumsi oleh berbagai jenis ikan dan udang. Fitoplankton dapat dibudidayakan bagi pembenihan ikan dan udang laut (Sub Balai Penelitian Budi Daya Pantai Bojonegara \& Japan Internasional Cooperation, 1985) Fitoplankton terbagi menjadi 2, yaitu Diatomae dan Dinoflagellata.

Plankton di perairan Teluk Jakarta ini sering menyebabkan kematian pada ikan, sehingga perlu diamati terus-menerus dari waktu ke waktu.

\section{POKOK BAHASAN}

\section{Alat dan Bahan}

Alat dan bahan yang digunakan dalam penelitian ini adalah net plankton (alat penyaring fito dan zoo), botol contoh fito isi $100 \mathrm{ml}$, botol contoh zoo isi 200 $\mathrm{ml}$ (Global Positioning System, formalin 40\%, ember ukuran $10 \mathrm{~L}$, botol semprot, kertas label, tali menali (tambang), dan spidol alat tulis-menulis.

\section{Teknik Pengambilan Contoh Plankton}

Sebelum pekerjaan pengambilan plankton terlebih dahulu supaya dipersiapkan alat dan bahan yang meliputi plankton net, botol contoh, ember, formalin $40 \%$, kertas label, dan spidol. Agar supaya contoh mewakili semua lokasi perairan, maka lokasi pengambilan contoh dipilih secara sistematis sesuai dengan variasi kondisi perairan dan dilakukan pada titik lokasi yang telah dirancang.

Pengambilan contoh plankton dapat dilakukan dengan 2 cara, yaitu pertama dengan cara ditimba dengan mempergunakan ember dan kedua dengan cara ditarik secara horisontal.

Dalam pengambilan contoh plankton pada setiap station dilakukan 2 kali yaitu untuk fitoplankton dan zooplankton, untuk pengambilan fitoplankton dengan plankton net berukuran mata saring 60 mikron, diameter mulut jaring $\pm 30 \mathrm{~cm}$, dan untuk zooplankton mata saring 100 mikron diameter mulut $\pm 80 \mathrm{~cm}$.

\section{Cara Pertama}

Cara pertama yaitu menggunakan ember isi $10 \mathrm{~L}$, air diambil atau ditimba memakai ember pada kedalaman $\pm 50 \mathrm{~cm}$ sampai permukaan badan air. Setiap kali menimba, air disaring dengan menggunakan plankton net. Pengambilan air diulang 10 kali ulangan sehingga total $100 \mathrm{~L}$. Setelah air disaring, air yang tertampung dalam cone plankton net lalu dipindahkan dalam botol contoh.

\section{Cara Kedua}

Dalam pengambilan cara kedua, plankton net diikat dengan tambang lalu ditarik minimal $10 \mathrm{~m}$ atau lebih secara horisontal, perhatikan posisi awal pengambilan contoh sampai dengan akhir.

Plankton net ditarik dengan kecepatan 1 knot (mil laut per jam). Setelah itu, air yang tersaring dalam cone plankton net dipindahkan ke dalam botol contoh. Supaya plankton di dalam jaring bersih, maka dilakukan pembilasan 3 kali. Lalu beri larutan formalin, catat nomor stasiun, tanggal, dan waktu pengambilan pada botol contoh tersebut.

\section{Pengawetan Contoh Plankton}

Contoh plankton di air tersaring yang sudah ada di dalam botol contoh diawetkan dengan larutan formalin $\pm 4 \%$. Caranya adalah dengan memasukkan larutan formalin $40 \%$ pada botol semprot ke dalam botol contoh tersebut, dengan perbandingan 1 bagian formalin $40 \%$ dan 9 bagian air yang tersaring, kemudian dikocok-kocok agar larutan formalin merata. Dengan pemberian formalin ini, contoh plankton akan utuh tidak rusak. 


\section{Identifikasi Plankton}

Plankton diidentifikasikan dengan mengacu pada Yamaji (1984). Pengamatan plankton menggunakan mikroskop elektrik binokuler dengan pembesaran $10 \times 10=100$ kali. Contoh plankton yang akan diamati terlebih dahulu diukur jumlah volume air tersaring yang ada pada botol contoh dengan gelas ukur.

Apabila ada endapan atau plankton padat, contoh diencerkan agar mudah dalam pengamatan dan penghitungan. Contoh diambil dengan pipet otomatis $1 \mathrm{ml}$ untuk diamati, lalu ditempatkan pada Sadgwich Rafter dan ditutup dengan coverglass. Plankton pada Sadgwich Rafter di bawah mikroskop lalu diaktifkan dan dihitung sesuai dengan urutan kotak di dalam Sadgwich Rafter.

Agar supaya plankton di bawah tampak jelas, maka sambil menghitung dilakukan pengaturan cahaya yang masuk ke dalam dengan memutar bagian pengaturan cahaya pada mikroskop.

\section{Penghitungan Kelimpahan Plankton}

Dalam penghitungan plankton ada 2 cara yaitu ditimba dengan ember dan ditarik secara horisontal. Jumlah kelimpahan dihitung masing-masing dalam $\mathrm{m}^{3}$, sedangkan satuan untuk fitoplankton per sel untuk zooplankton per individu.

\section{Rumus Pertama}

Rumus pertama yaitu dengan menggunakan ember dengan cara ditimba.

Jumlah volume contoh $x$ Jumlah sel hasil pengamatan $\times 1 \mathrm{~m}^{3}$

Jumlah volume pengamatan $(1 \mathrm{ml}) \times$ vol air yang disaring $(\mathrm{m})^{3}$.....

\section{Contoh dalam Penghitungan}

1. Jumlah volume contoh tersaring $85 \mathrm{ml}$.

2. Jumlah dalam pengamatan $1 \mathrm{ml}$.

3. Dalam pengamatan $1 \mathrm{ml}$ terdiri atas chaetoceros 250 sel.

Jadi dalam penghitungan sebagai berikut:

$$
\begin{aligned}
\text { Chaetoceros } & =\frac{85 \mathrm{ml} \times 250 \mathrm{sel} \times 1 \mathrm{~m}^{3}}{1 \mathrm{ml} \times 0,1 \mathrm{~m}^{3}} \\
& =\frac{21.250}{0,1} \\
& =212.500 \mathrm{sel} \mathrm{m}^{-3}
\end{aligned}
$$

\section{Rumus Kedua}

Rumus kedua yaitu dengan cara ditarik secara horisontal minimal $10 \mathrm{~m}$ atau lebih.

Untuk penghitungan cara kedua ini pertama kali menentukan volume air yang tersaring yaitu:

Volume air yang disaring = luas mulut jaring $x$ panjang yang ditempuh

$$
=\frac{22}{7} \times 0,15 \times 0,15 \times 10 \mathrm{~m}
$$

Jadi rumus:

$=$ jumlah volume contoh $\mathrm{x}$ jumlah sel hasil pengamatan $\times 1 \mathrm{~m}^{3}$

Jumlah volume pengamatan $(1 \mathrm{ml}) \times$ volume air yang disaring $(\mathrm{m})^{3}$

\section{Contoh dalam Penghitungan}

1. Jumlah volume contoh $172 \mathrm{ml}$.

2. Jumlah dalam pengamatan $1 \mathrm{ml}$.

3. Dalam pengamatan $1 \mathrm{ml}$ terdiri atas Acartia 150 individu.

Jadi dalam penghitungan sebagai berikut:

$$
\begin{aligned}
\text { Acatia } & =\frac{172 \mathrm{ml} \times 150 \text { individux } 1 \mathrm{~m}^{3}}{1 \mathrm{ml} \times 0,70 \mathrm{~m}^{3}} \\
& =\frac{25.800}{0,7} \\
& =36.857 \mathrm{ind} . \mathrm{m}^{-3}
\end{aligned}
$$

\section{Hasil Pengamatan}

1. Pengamatan fitoplankton pada 12 stasiun di perairan Teluk Jakarta pada bulan Desember 2005 diperoleh total kelimpahan dari $6.796 .267 \mathrm{sel} \mathrm{m}^{-3}$ dengan 21 jenis marga sampai 61.502 .614 sel $\mathrm{m}^{-3}$ dengan 17 jenis marga (Tabel 1 ).

2. Pengamatan zooplankton diperoleh total kelimpahan 2.901 ind. $\mathrm{m}^{-3}$ dengan 8 jenis marga, sampai 12.902 ind. $\mathrm{m}^{-3}$ dengan 6 jenis marga (Tabel 2).

3. Sedangkan kelimpahan yang paling dominan pada fitoplankton didapat pada stasiun 11 dan pada zooplankton didapat pada station 1. 


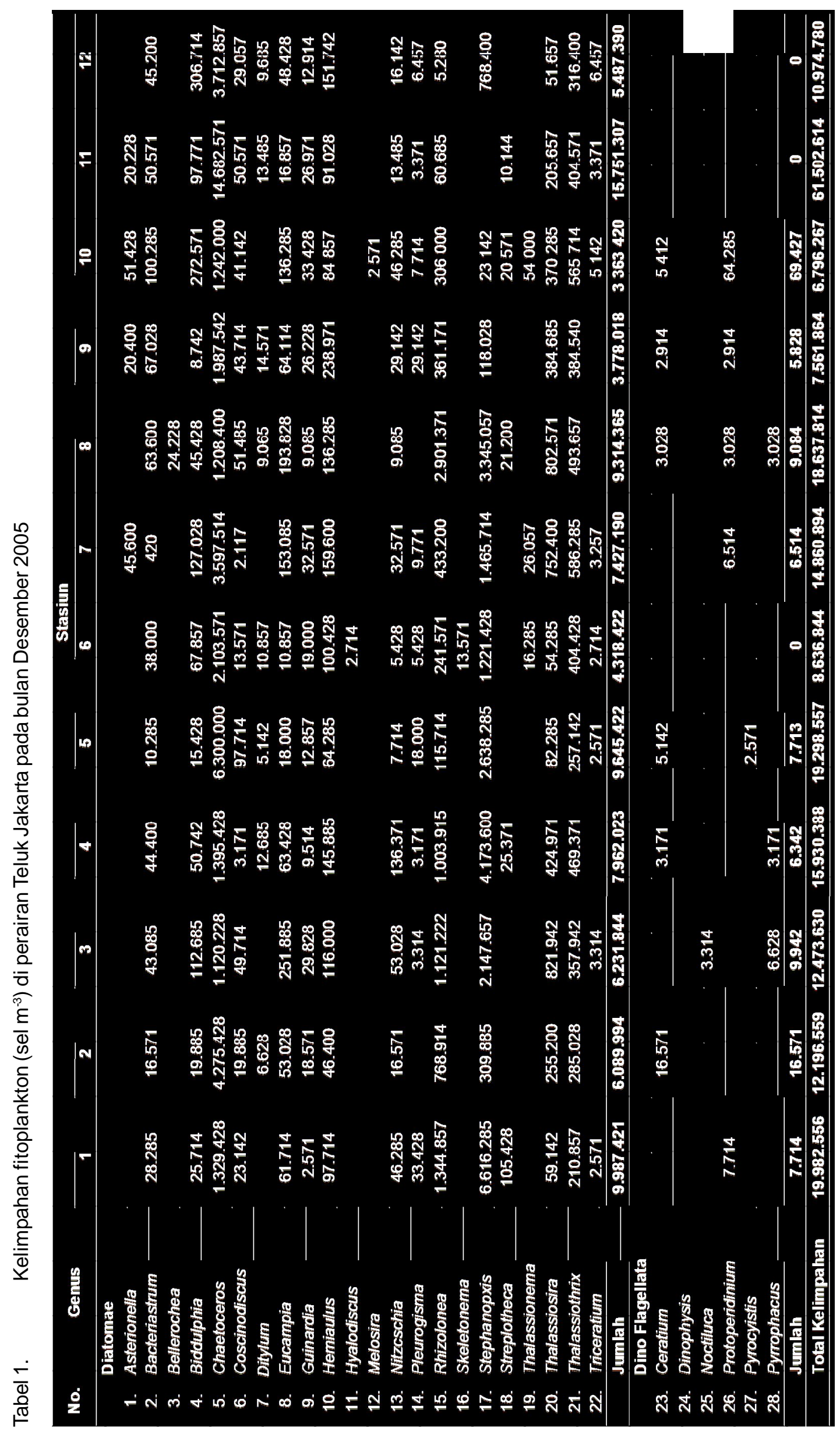




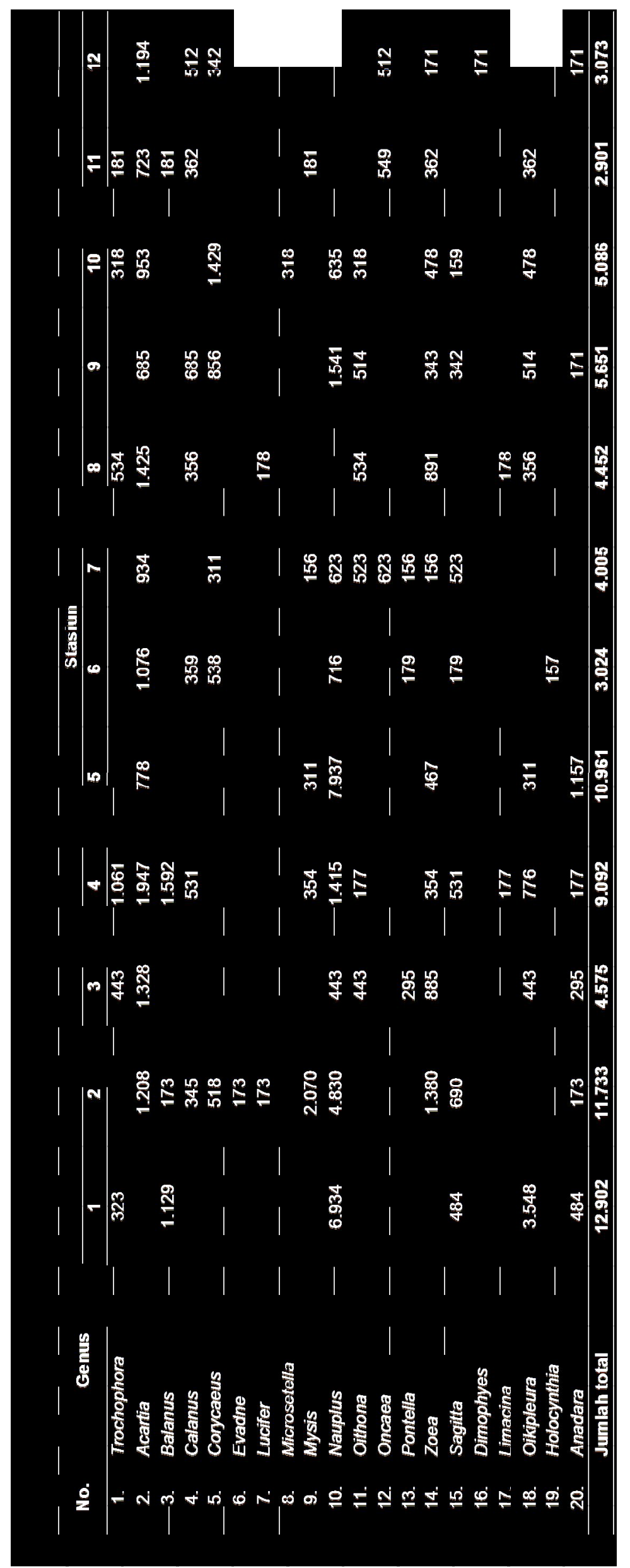




\section{KESIMPULAN}

1. Kelimpahan fitoplankton di Teluk Jakarta pada bulan Desember 2005 berkisar 2.117-14.682.271 sel $\mathrm{m}^{-3}$ dan didominansi oleh Chaetoceros.

2. Kelimpahan zooplankton berkisar 156-6.934 ind. $\mathrm{m}^{-3}$, dan didominansi oleh jenis Nauplius.

\section{DAFTAR PUSTAKA}

Sub BPBP Bojonegara \& JICA. 1985. Budi daya fitoplankton. Sub Balai Penelitian Budi Daya Pantai Bojonegara dengan Japan.

Yamazi I. 1984. Ilustrations of the Marine Plankton of Japan. Hokusha Publishing Ltd. Osaka Japan 